\title{
Концентрические гексагональные структуры GaN для нанофотоники, изготовленные селективной газофазной эпитаксией с использованием ионного травления
}

\author{
(C) М.И. Митрофранов ${ }^{1,2}$, Я.В. Левицкий ${ }^{1,2}$, Г.В. Вознюк ${ }^{3}$, Е.Е. Татаринов ${ }^{3}$, С.Н. Родин ${ }^{1,2}$, \\ М.А. Калитеевский ${ }^{1,3,4, \uparrow, ~ В . П . ~ Е в т и х и е в ~}{ }^{1}$ \\ ${ }^{1}$ Физико-технический институт им. А.Ф. Иоффре Российской академии наук, \\ 194021 Санкт-Петербург, Россия \\ ${ }^{2}$ НТЦ микроэлектроники Российской академии наук, \\ 194021 Санкт-Петербург, Россия \\ ${ }^{3}$ Санкт-Петербургский национальный исследовательский университет \\ информационных технологии, механики и оптики (Университет ИТМО), \\ 197101 Санкт-Петербург, Россия \\ ${ }^{4}$ Санкт-Петербургский национальный исследовательский Академический университет \\ Российской академии наук, \\ 194021 Санкт-Петербург, Россия \\ ฯ E-mail: Kalit@mail.ioffe.ru
}

(Получена 18 декабря 2017 г. Принята к печати 18 декабря 2017 г.)

\begin{abstract}
Методом селективной газофазной эпитаксии в окнах, сформированных сфокусированным ионным пучком, в слое $\mathrm{Si}_{3} \mathrm{~N}_{4}$ были сформированы коаксиальные и одиночные $\mathrm{GaN}$-структуры субмикронных размеров гексагональной формы с пирамидальными гранями. Установлено, что при росте структур в окнах маски, имеющих кольцевую форму, в процессе роста происходит формирование коаксиальных гексагональных структур.
\end{abstract}

DOI: $10.21883 /$ FTP.2018.07.46058.8797

Создание наноструктур для изготовления электронных и оптоэлектронных приборов является многоступенчатым процессом, включающим в себя проведение эпитаксиального роста многослойной структуры на подложке, литографии и постростовых процессов. Альтернативным способом изготовления трехмерных полупроводниковых наноструктур является селективная эпитаксия [1-5], а также процессы с самоорганизацией структур, позволяющие выращивать квантовые точки [6] и квантовые проволоки [7,8]. Перспективным методом формирования наноструктур на основе $\mathrm{GaN}$, значительно более быстрым, чем электронная литография [9], является селективная газофазная эпитаксия [10], при которой заданный рисунок окон в маске наносится посредством травления сфокусированным ионным пучком (СИП) [11]. Цель данной работы — разработка на основе этого метода технологии изготовления коаксиальных GaN-структур.

Последовательность процессов, использовавшихся для получения структур, схематично показана на рис. 1. Сначала на сапфировой подложке с ориентацией (0001) стандартным методом газофазной эпитаксии из металлорганических соединений (ГФЭМОС) выращивался буферный слой $\mathrm{GaN}$ толщиной 3 мк. Буферный слой легировался кремнием до концентрации $n=2 \cdot 10^{17} \mathrm{~cm}^{-3}$, что необходимо для предотвращения заряда подложки при последующем ионном травлении, так как накапливающийся на поверхности электрический заряд может приводить к расфокусировке и отклонению ионного пучка. Поверх буферного слоя in situ наносилась маска из нитрида кремния $\left(\mathrm{Si}_{3} \mathrm{~N}_{4}\right)$, при этом в качестве источников кремния и азота использовались силан $\left(\mathrm{SiH}_{4}\right)$ и аммиак $\left(\mathrm{NH}_{3}\right)$. Осаждение слоя маски проводилось при температуре $1000^{\circ} \mathrm{C}$. Для изготовления окон в слое $\mathrm{Si}_{3} \mathrm{~N}_{4}$ использовалась методика травления сфокусированным ионным пучком в сверхвысоком вакууме. Пучок ионов $\mathrm{Ga}$ c энергией 30 кэB с током 450 пА фокусировался в круг диаметром 40 нм. Доза облучения образца при травлении составляла 45 пК/мкм². Для предотвращения образования капель галлия на поверхности маски на область травления направлялся поток дифторида ксенона, как показано на рис. 1. Сканирование пучком ионов $\mathrm{Ga}$ по поверхности позволяло формировать в в маскирующем слое окна произвольной геометрии с разрешением $\sim 5$ нм, различающиеся конфигурацией, взаимным расположением, геометрическими размерами шириной, длиной и глубиной протрава.

Затем методом ГФЭМОС осуществлялся селективный рост $\mathrm{GaN}$ [12]. В качестве источников азота и галлия использовались аммиак $\mathrm{NH}_{3}\left(200 \mathrm{~cm}^{3} /\right.$ мин $)$ и триметилгаллий $\mathrm{Ga}\left(\mathrm{CH}_{3}\right)_{3}$ (60 мкмоль/мин), а в качестве газаносителя - водород $\left(6000 \mathrm{~cm}^{3} /\right.$ мин $)$. Давление в реакторе составляло 100 мбар, температура подложки $1030^{\circ} \mathrm{C}$.

Для селективного роста нитрида галлия использовались два типа окон. С целью предотвращения взаимного влияния расстояние между ними значительно превышало их геометрические размеры.

- Первый тип - „крест“ - две взаимно перпендикулярные полосы длиной 200 мкм, шириной > 100 нм каждая, вытравленные без заглубления в буферный слой $\mathrm{GaN}$. Одна из полос ориентирована вдоль направления [0110]. 
conventional MOCVD

\begin{tabular}{|c|}
\hline $\mathrm{Si}_{3} \mathrm{~N}_{4}$ mask layer \\
\hline GaN buffer layer \\
\hline Sapphire substrate \\
\hline
\end{tabular}

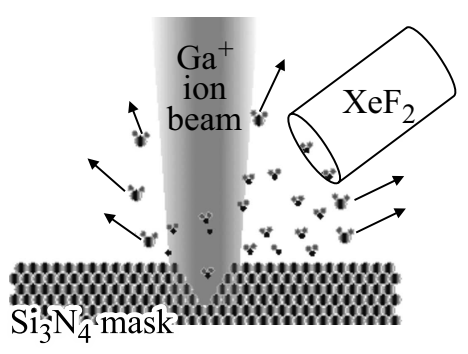

selective MOCVD

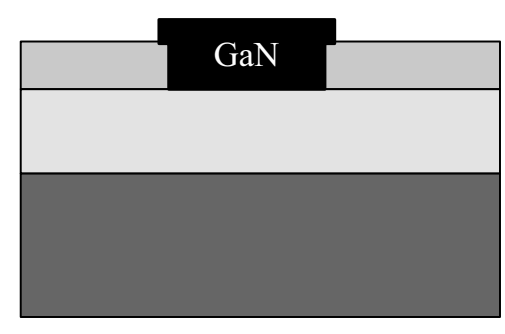

Рис. 1. Последовательность процессов, использованных для получения структур. Слева - на сапфировой подложке выращивается буферный слой $\mathrm{GaN}$; в центре - методом ионной спектроскопии в маске вытравливается открытая область. Справа — в открытой области методом селективной газофазной эпитаксии выращивается $\mathrm{GaN}$.

$a$

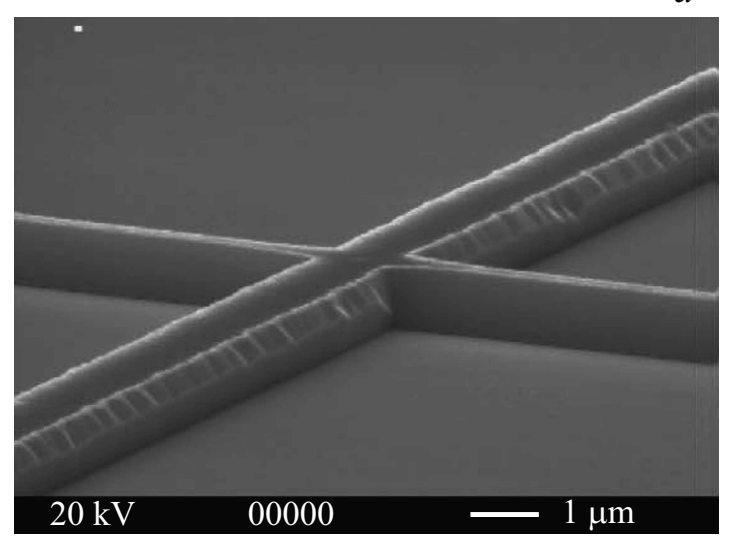

$c$

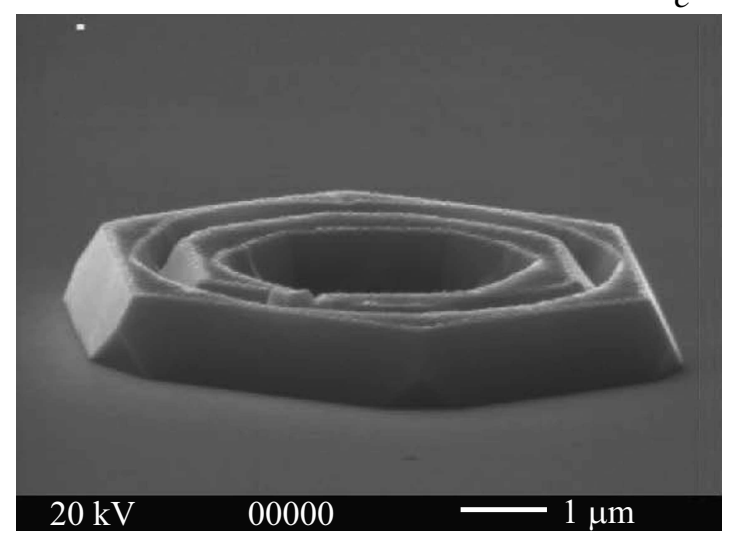

$b$

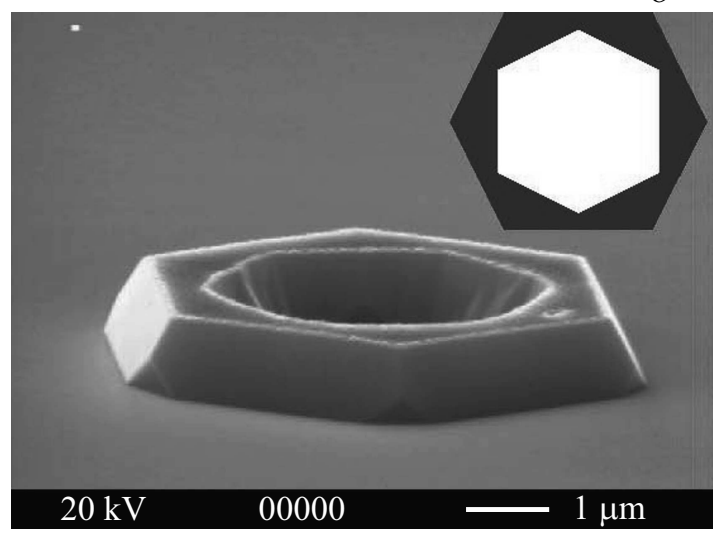

$d$

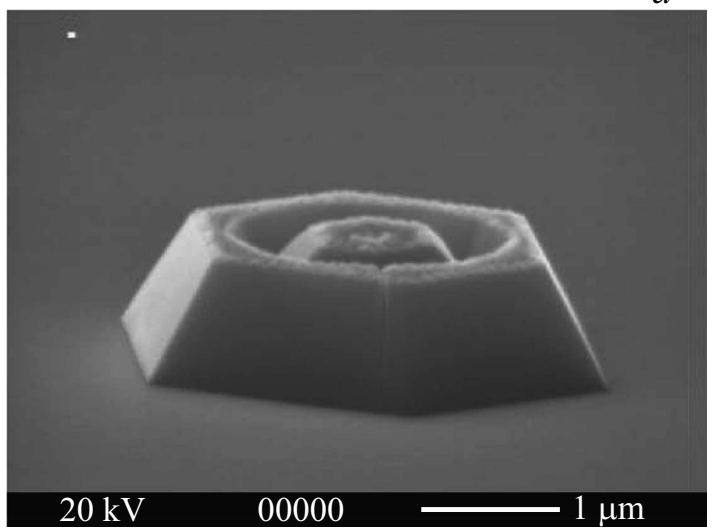

Рис. 2. SEM-изображения структур, полученных селективной газофазной эпитаксией с использованием ионного травления для разных типов окон. Все изображения получены на одном образце в одном ракурсе. $a$ - „крест“ - две взаимно перпендикулярные полосы длиной 200 мкм, шириной > 100 нм каждая, вытравленные без заглубления в буферный слой GaN. Горизонтальная полоса ориентирована вдоль направления $[0110] \mathrm{GaN} .(b, c, d)$ „кольца“: с внутренним диаметром $(b)-5$ мкм, $(c)-5$ мкм с заглублением, $(d)-1.5$ мкм с заглублением. Вставка на рис. $2, b$ иллюстрирует расположение граней на внешней и внутренней поверхностях структуры.

- Второй тип - „кольца“ - 3 группы кольцевых окон. Внутренний диаметр колец в первой группе (А) - 5 мкм, во второй (В) - 5 мкм с заглублением в буферный слой $\mathrm{GaN}$, в третьей $(\mathrm{C})-1.5$ мкм с заглублением в буферный слой GaN. Ширина колец составляла $>100 \mathrm{Hм}$.
Выращенные структуры исследовались с помощью сканирующего электронного микроскопа (SEM) CamScan3000, их изображения представлены на рис. 2.

Разная форма полосков нитрида галлия на взаимно перпендикулярных полосах („крест“ (рис. 2,a)) наглядно демонстрирует различие скорости роста кристалли- 
ческого $\mathrm{GaN}$ в различных направлениях Поперечное сечение полоска $\mathrm{GaN}$, сформировавшегося вдоль направления базового среза, представляет собой равнобедренную трапецию. Боковые наклонные грани образованы

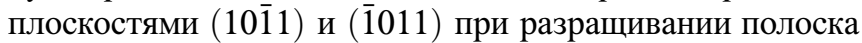
вбок над поверхностью маски. В то же время боковые поверхности перпендикулярного ему полоска $\mathrm{GaN}$

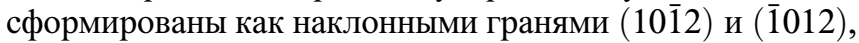

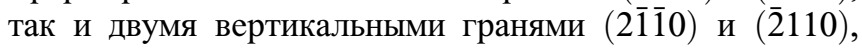
доходящими примерно до половины его высоты.

На рис. 2, $b$ показана структура, выращенная на втором типе окон в маске - незаглубленные „кольца“, группа А. Описанная выше анизотропия роста приводит к формированию структуры гексагональной формы. Разрез структуры в плоскости подложки имеет вид кольца, образованного двумя правильными шестиугольниками с общим центром, повернутыми друг относительно друга на $30^{\circ}$. Ширина такого шестигранного кольца составляла от $\sim 1.5$ до $\sim 0.5$ мкм. В целом формирование гексагональных структур на изотропных масках в базовой плоскости характерно для селективного роста вюрцитных кристаллов, к которым относится $\mathrm{GaN}$.

Совершенно иначе выглядят структуры (рис. 2,c), выращенные на той же подложке и в том же эпитаксиальном процессе, в окнах того же размера (группа В), однако вытравленные на бо́льшую глубину. В этом случае боковые стенки травленой области состоят не только из слоя маски, но и из подслоя $\mathrm{GaN}$. Большая разница в скоростях роста на поверхностях (0001) (дно затрава) и боковых стенках приводит к преимущественному росту на стенках затрава и формированию двух коаксиальных шестигранных колечек, подобных описанным выше для типа А. Причем разделение этих колечек происходит ровно посредине исходного кольцевого окна.

Для окон группы C с минимальным диаметром кольца (1.5 мкм) боковое разращивание приводит к практически сплошному заполнению центральной полости (рис. 2,d).

Так как продемонстрированный способ роста аналогичен хорошо зарекомендовавшему себя методу ELOG, мы полагаем, что полученные структуры должны иметь низкую плотность дислокаций.

Структуры подобной формы могут быть использованы для создания микрорезонаторов, способных эффективно локализовывать свет. Подобные структуры могут обладать рядом преимуществ перед микродисками [13], а также цилиндрическими [14] или сферическими [15] брэгговскими отражателями, так как снятие круговой симметрии в шестигранных структурах изменит модовый состав резонатора и сделает его более контролируемым.

Таким образом, в работе установлено, что сочетание метода ионно-лучевой литографии и последующего бокового разращивания при селективной эпитаксии ГФЭМОС нитрида галлия позволяет создавать коаксиальные гексагональные кольцевые структуры микронного и субмикронного размеров.

Авторы выражают благодарность Российскому научному фонду (грант 16-12-10503), С.И. Трошкову и В.В. Лундину за полезные обсуждения.

\section{Список литературы}

[1] S.F. Li, A. Waag. J. Appl. Phys., 11 (7), 071101 (2012).

[2] J.P. Duchemin, M. Bonnet, F. Kielsch, D.H. Huyghe. J. Cryst. Growth, 45, 181 (1978).

[3] K. Kamon, S. Takagish, H. Mori. J. Cryst. Growth, 73, 73 (1985).

[4] Y.D. Galeuchet, P. Roentgen, V. Graft. J. Appl. Phys., 68, 560 (1990).

[5] Л.Б. Проэкт, М.А. Калитеевский, В.Б. Кантор, Д.А. Пиотровский, М.А. Синицын, Б.С. Явич. ФТП, 31 (4), 470 (1997).

[6] H. McKay, P. Rudzinski, A. Dehne, J.M. Millunchick. Nanotechnology, 18, 45 (2007).

[7] G.E. Cirlin, V.G. Dubrovskii, Y.B. Samsonenko, A.D. Bouravleuv, K. Durose, Y.Y. Proskuryakov, B. Mendes, L. Bowen, M.A. Kaliteevski, R.A. Abram. Phys. Rev. B, 82, 35302 (2010).

[8] V. Neplokh, A. Ali, F.H. Julien, M. Foldyna, I. Mukhin, G. Cirlin, J.-C. Harmand, N. Gogneau, M. Tchernycheva. Mater. Sci. Semicond. Process., 55, 72 (2016).

[9] F. Barbagini, A. Bengoechea-Encabo, S. Albert, J. Martinez, M. Garcia, A. Trampert, E. Calleja. Nanoscale Res. Lett., 6, 1 (2011).

[10] H. Amano. Angew. Chem. Int. Ed., 54, 7764 (2015).

[11] I. Utke, P. Hoffmann, J. Melngailis. J. Vac. Sci. Technol. B Microelectron. Nanom. Struct. Process. Meas. Phenom., 26, 1197 (2008).

[12] M.I. Mitrofanov, S.N. Rodin, I.V. Levitskii, S.I. Troshkov, A.V. Sakharov et al. J. Phys.: Conf. Ser., 816, 012009 (2017).

[13] А.М. Надточий и др. Письма ЖТФ, 39 (18), 70 (2013).

[14] M.A. Kaliteevski, R.A. Abram, V.V. Nikolaev. J. Modern Optics, 47 (4), 677 (2000).

[15] M.A. Kaliteevski, S. Brand, R.A. Abram, V.V. Nikolaev. J. Modern Optics, 48 (9), 1503 (2001).

Редактор А.Н. Смирнов

\section{Concentric hexagonal structures GaN for nanophotonics, made by gas phase epitaxy with ion beam etching}

\author{
M.I. Mitrofanov ${ }^{1,2}$, I.V. Levitskii ${ }^{1,2}$, G.V. Voznyuk ${ }^{3}$, \\ E.E. Tatarinov ${ }^{3}$, S.N. Rodin ${ }^{1,2}$, \\ M.A. Kaliteevski ${ }^{1,3,4}$, V.P. Evtikhiev ${ }^{4}$ \\ ${ }^{1}$ loffe Institute, \\ 194021 St. Petersburg, Russia \\ 2 SHM R\&E Center Russian Academy of Sciences, \\ 194021 St. Petersburg, Russia \\ 3 ITMO University, \\ 197101 St. Petersburg, Russia \\ ${ }^{4}$ St. Petersburg National Research Academic University, \\ Russian Academy of Sciences \\ 194021 St. Petersburg, Russia
}

Abstract Coaxial and single $\mathrm{GaN}$ submicron structures of hexagonal shape with pyramidal facets were realized using selective vapor phase epitaxy in conjunction with focused ion beam method. It was found that coaxial hexagonal structures are formed during growth process in ring shaped mask windows. 